\title{
ON ANTI-INTELLECTUALISM, CULTISM, AND ONE-SIDED THINKING: O'REGAN REPLIES
}

O’Regan. J. P. (2015). On anti-intellectualism, cultism, and one-sided thinking. O’Regan replies Applied Linguistics 36 (1), 128-132.

I have been asked to respond to two forum pieces, one by Henry Widdowson and another by Will Baker, Jennifer Jenkins and Robert Baird concerning my article 'English as a lingua franca: an immanent critique' in Applied Linguistics 35(2014). Let me begin then by saying that once the Applied Linguistics editors informed me that my article was being accepted for publication, I expected that there would be a response. 'ELF' researchers have been nothing if not assiduous in leaping to defend 'ELF' whenever it is questioned, as readers familiar with this field of research will know. So to receive a response from a group of 'ELF' researchers is something of a vindication that my article hit its mark. The reaction of Widdowson was less expected, but more because of the mimetic manner in which it was carried out, than the fact of the reply itself. In Widdowson's piece there is some superficial engagement with my article in respect of hypostatization and immanent critique, but this would appear to be little more than a pretext for his main objective, which is to question my scholarship and to accuse me of Marxist epistemological fundamentalism.

On the first point, I have nothing to say; others can decide. On the second, Widdowson implies that my being a member of a Marx reading group at my university makes me and my colleagues Marxists, and that (because of this?) we do not engage in, 'responsible critical thinking' (p. 4). I consider this to be representative of a type of anti-intellectualism whereby unwelcome theoretical ideas may be discounted simply on account of being unwelcome theoretical ideas. It seems for Widdowson that the mere mention of Marx or Marxism is argument enough, and as such is a sufficient basis upon which appropriately damning conclusions about what I have to say may be inferred. Given the deliberate multiperspectivism which I have applied to my discussions of epistemology and truth in my article, and how different epistemological positions seem profoundly confused in 'ELF' literature, I find it difficult to treat his discussion seriously. Still less so when he appears to equate the thinking of Marx with that of Ron Hubbard, the founder of the Scientology cult.

In my article I had a serious point to make; one which in an odd way Widdowson's response authenticates. This is that in the writings of 'ELF' researchers, the concept of 'ELF' is projected as an hypostatized thing-in-itself. That is to say, that despite repeated references to the observed hybridity, fluidity, and flexibility of the language forms being described, users of English(es) in multicultural settings are presented in 'ELF' literature as if they are speakers or users of a presupposed 'ELF' variety. But rather than dealing with the implications this has for 
'ELF' and 'ELF' theory, which was what my article was about, Widdowson's response is that hypostatizations are everywhere, and that my article abounds in them. I agree that concepts such as power, reality, and English itself, can be treated as hypostatizations. All abstract concepts have this potential. When, for example, Foucault says, 'Far from preventing knowledge, power produces it' (1980: 59), it could be argued that he is hypostatizing power, but this in itself does not bring Foucault's theory of power crashing down about his ears. For that to happen, you would have to show that the hypostatization itself is somehow fatal to his argument about power, which I would argue it is not.

The obverse, however, is true of 'ELF'. Here is an hypostatization which is fatal to itself, and it is this which my immanent critique of 'ELF' identifies. This shows that there is a fundamental contradiction which ensues from the ubiquitous hypostatization of 'ELF' in 'ELF' research, of appearing to treat 'ELF' as if it were a variety while simultaneously insisting that it is not, or by simply relying on it being obvious that 'ELF-as-a-variety' is not what is meant by 'ELF'. It seems then that even though 'ELF' is not to be understood as a thing-in-itself, in the discourse of 'ELF' researchers it will nevertheless be written about as if it were a thing-in-itself. This seems a little too convenient, and while it may work well enough for the purposes of recruitment to the 'ELF' project, and perhaps give 'ELF' researchers a feeling of moral certitude, it makes for muddled thinking. In sum then, from what I have said it should be apparent that Widdowson's immanent critique of my article fails because he is unable to demonstrate that the so-called hypostatized concepts which he believes he detects in my article undermine my argument about the hypostatization of 'ELF' and the consequences this has for this field of research. 'ELF' thus remains hypostatized and problematic regardless of his critique.

Baker, Jenkins \& Baird take a similar tack to Widdowson. Rather than dealing with any of the substantive points: the ideological fetishism of 'ELF', the elitism of 'ELF' research, the conflation of learners with users in 'ELF' literature, the near total neglect of the political economy of English(es) under conditions of neoliberal global capitalism, and the central issues of theoretical incommensurability and epistemological contradiction, they prefer instead to push the discussion elsewhere. This is not new: it has become customary in defences of 'ELF' that its detractors are accused of misinterpreting and misunderstanding 'ELF'; so that rather than dealing with the fundamentals of whatever critique has been made, the debate is instead diverted to another space which usually has little direct relevance to the original critique. The Baker, Jenkins \& Baird piece is a good example of this kind of 'ELF' response. Their focus is on my supposed 'misinterpretations of ELF' (p. 1), my use of the term 'ELF movement' (p. 1), how my article reveals its own 'inconsistencies and contradictions' (p. 2), and how I misrepresent 'ELF' research when I accuse 'ELF' researchers of a lack of theoretical engagement in questions of ideology, discourse, power, truth and the nature of the real, as well as the relations between 
them (p. 2). Only on the last point do they speak to a substantive argument of my article, but as I will show, they do so only in a superficial and selective way. Whatever the merits or otherwise of the arguments which the authors of this second response make, they do not in my view deflect the critique which I make in my article, or lessen its force. It is worth repeating what the main points of my critique are: 1) 'ELF' is problematically hypostatized in 'ELF' research as a seemingly stable form and this leads 'ELF' researchers into performative contradiction; 2) In 'ELF' literature the political economy of English(es) under conditions of neoliberal global capitalism has been neglected; 3) In 'ELF' theory a rationalist, positivist and objectivist epistemology has been combined with a transformationalist, postmodern and poststructuralist sensibility which is incommensurable and undertheorized.

To suggest that I have misinterpreted 'ELF' when I show that it is hypostatized in 'ELF' research is thus to miss the point of my critique. I also do not argue or imply in relation to hypostatization that 'ELF' is, 'a static homogenous field of inquiry' (p. 1); this is not a theme of my article. My purpose was instead to demonstrate that there is a fundamental contradiction between the claim to fluidity, hybridity and flexibility amongst usages described as 'ELF' in the literature and the term 'ELF' itself, particularly when 'ELF' researchers so easily employ expressions such as 'ELF speakers', 'ELF settings', 'ELF interactions', and 'ELF' as 'an emerging English', and so on in their writing. In addition, rather than evaluating 'ELF' as a static and homogenous field, I wished to show that it was anything but, and that a fundamental problem is the field's lack of an integrated coherence and commensurability. To come full circle then, if any misinterpretation is at issue, the cause of this lies squarely at the door of 'ELF' researchers themselves for their own hypostatization of 'ELF' and the incommensurability of their theoretical positions. The only way to address the former would be for the field to give up 'ELF' as a term, since it is evidently inadequate to its concept. As for the latter, I come to this below.

I appreciate that Baker, Jenkins \& Baird, while liking the term 'ELF', dislike the term 'ELF movement', but as they note, and as I reference in my article, it is an appellation I did not think up myself. The reason I adopted the phrase is because there was a sense in which the 'ELF' project - in its moral certitude, its peculiar defensiveness, and in its fetishism of the 'ELF' concept itself - appeared to me to be somewhat cultish, and so it seemed an apt description to use in relation to the field and the arguments I wished to make about it. It is the perceived cultism of 'ELF' that for me explains a) the idealist rationalism, hypostatization, and fetishism of 'ELF', b) the projection of its detractors as purveyors of misinterpretations, and c) the selective manner in which its defenders engage with criticism of 'ELF'. Thus, rather than dealing with the core issues which my article raises, my critics move the terms of the debate elsewhere, to the manner of the argument and the supposed ideological attachments of the person who is responsible for it. So, they accuse me of advocating, 'one single approach to theorization and 
research' (p. 2), and of disagreeing with 'ELF' approaches, 'because they do not accord with his own Marxist understanding of the issues' (p. 2). This is the fundamentalist insinuation of the Widdowson response reprised.

It is convenient too, because by placing the onus on Marxism, both responses are able to ignore the poststructuralist dimensions of my critique. A key argument in my article is that in a good deal of writing about 'ELF', poststructuralist perspectives, for example on globalization and postcolonialism, are problematically meshed with positivist and empiricist perspectives on knowledge and truth, so that the result is a theoretical discourse and politics of knowledge which is in contradiction with itself. If these different positions are to be placed together, then there is a need in 'ELF' research to deal at a theoretical level with issues of ideology, discourse, power, reality, and truth, and what these mean for 'ELF'. Seen in this light, the idea that my article works on the basis of 'a priori assumptions' (p. 2) or that I advocate a single explanation of the above concepts does not bear close examination. I have been careful to deal with 'ELF' from a multiperspectival position which as I state at the outset includes Marxism and poststructuralism. I do this precisely because of the kinds of problems which I have found with 'ELF' epistemology and theory in the many accounts of 'ELF' which I have read. My argument is that 'ELF' as a field needs to be able to give a commensurable account of ideology, discourse, power, truth and the nature of the real, as well as the relations between them, particularly if 'ELF' researchers wish to invoke a poststructuralist sensibility in relation to 'ELF'. That the meaning of these terms is contingent upon theory and that there are no single explanations of them is fundamental to the problematic which my critique outlines, and so for Baker, Jenkins \& Baird to accuse me of $a$ priori thinking is to demonstrate a theoretical one-sidedness in their approach; one which leaves my own critique concerning the incommensurable nature of 'ELF' theory intact.

Baker, Jenkins \& Baird close their piece with the claim that with regard to ideology, discourse, power, truth and the nature of the real, '[Author] is wrong to suggest that these are issues on which those involved in ELF inquiry have remained silent. Questions of standard language ideology, native speaker ideology and indeed the ideology of ELF scholars themselves have all been subjects of discussion and debate' ( $\mathrm{p} 2$ ). This deserves some comment. First of all, were it the case that these concepts had been discussed in 'ELF' literature in anything more than a superficial manner, then my article would not have been necessary. But the fact is that they had not, as my article documents at some length. Second, the authors only reference ideology, nothing else. What of discourse, power, truth and the nature of the real, as well as the relations between them? I have found no theoretical account of this in the literature to date. Third, ideology as presented in their response can principally be understood as opinion-based and untheorized. What is absent, as is the case in the wider 'ELF' literature, is a more theoretically- 
nuanced explication of ideology as, for example, backgrounded common sense, subject position, habitus, discourse, or interpellation. To give them their due however, Baker, Jenkins \& Baird are correct to state that, '[Author] imposes a theoretical and philosophical framework on ELF as a field of inquiry that is not one the majority of ELF researchers would recognize' (p. 2). That - at least in part - was the point of my critique, since the absence of an appreciation of theory in 'ELF' research is highly apparent. Finally, I also wish to suggest, as it seems do the authors, that applied linguistics is interdisciplinary, and as much as this is so, it is therefore entirely realistic to expect 'ELF' as a field of inquiry to be held accountable in respect of theoretical and epistemological positions which 'ELF' researchers have themselves invoked.

\section{References}

Foucault, M. 1980. Power/Knowledge: selected interviews and other writings, 1972-1977. C. Gordon (ed.). The Harvester Press.

O'Regan, J. 2014. 'English as a Lingua Franca: an immanent critique,' Applied Linguistics doi:101093/applin/amt045. 